\title{
NETWORK BROADCASTING-THE REPORT OF THE FCC NETWORK STUDY STAFF
}

\author{
ROSCOE L. BARROW*
}

I

INTRODUCTION

In the fall of 1955, the Federal Communications Commission initiated a comprehensive study of television network broadcasting. ${ }^{1}$ The study was made in order to determine whether the present operation of television networks and their relationships with stations and other components of the industry tend to foster or impede the development of a nation-wide, competitive broadcasting system. The findings and recommendations resulting from the study are set forth in Network Broadcasting. ${ }^{2}$ The report was submitted on October 3, 1957, to the Network Study Committee of Commissioners. ${ }^{3}$ Thereafter, the Committee referred the report to the Commission as a whole. On January 8 , 1958 , the Commission announced public hearings $s^{4}$ on the matters contained in the report, such hearings to begin on March 3, 1958, and to be before the Commission en banc.

It is the purpose of this article to sketch in broad brush strokes why and how the television network study was made, the major recommendations contained in the report, and the significance of the proposed changes for broadcasting service.

II

\section{Why the Study Was Made}

The study was made, primarily, because no comprehensive study of television broadcasting, for purposes of determining the efficacy of the Commission's rules in achieving legislative and commission policy, had ever been made. The Chain Broadcasting Rules resulted from the study, conducted from $193^{8}$ to r941, of radio broadcasting. When television became a commercial medium, these radio rules were applied to television without any changes, although there are marked differences between television and radio. A medium employing sound alone cannot be equated with a medium using sight, sound, and motion. From the regulatory standpoint,

- B.S.(A.S.) 1935, Illinois Institute of Technology; J.D. 1938, Northwestern University. Dean and Professor of Law, University of Cincinnati; member of the Ohio bar. Contributor to legal periodicals.

${ }^{1}$ Network Study Committee Order No. I, FCC 55 No.-978, November 21, 2955, Network Broadcasting, Exhibit 2 (a). It was originally contemplated that the study would encompass radio as well as television networks. However, limitations of time and staff required a concentration on the more pressing problems, which were in television. Congress provided for the study through a special appropriation. 69 STAT. 20I (r955).

* FCC, Network Broadcasting, Report of the Network Study Stafi to the Network Study CoMmitee (1957).

${ }^{8}$ FCC Delegation Order No. ro, FCC 55-810, July 22, I955, Network Broadcasting, Exhibit I, established a Committee of Commissioners and referred to this Committee responsibility for the study.

'Notice of Public Hearing FCC 58-37, Docket No. 22285, released Jan. 9, 1958. 
two simple facts, inter alia, illustrate the difference. There are more than six times as many radio stations as there are television stations. The greater scarcity of television outlets creates special problems. The cost of television programming is several times that of radio programming. The high cost of television programming renders television stations more dependent on networks for programming than radio stations are. A vital new industry, television has developed under a statute and regulations which were not designed in the light of the structure and practices in television and the related problems. Thus, a study was necessary to determine whether the radio rules are achieving congressional and commission policy in television. An additional reason for the study was to lay a basis for informed comments by the Commission on bills introduced in the past three congresses and providing for the direct regulation of networks.

III

\section{How the Study Was Made}

The study was made by a special staff of professional personnel recruited from universities, government, and industry and selected with the objective of giving to the study a well-rounded viewpoint.

The general philosophy underlying the study was to accept the network system of broadcasting, supported by advertising; to determine whether and to what extent the existing practices under this system obstruct the effectuation of legislative and Commission policies; and to recommend the minimum changes necessary to attain the optimum broadcasting performance in the public interest under the existing broadcästing system.

To a considerable extent, public policy leaves regulation of broadcasting to the free interplay of competitive forces. Hence, the regulatory approach in broadcasting must be, largely, to assure that there are opportunities for competition between and among networks and between networks and other components of the industry. Accordingly, the study encompasses the structure, operations, and practices of networks and their relationships with other components of the industry. These are evaluated in the light of the doctrines through which the Commission has sought to give substance to the legislative policy of the "public interest" served by broadcasting. The basic problem is whether under the existing structure and practices of the industry, there is effective competition, and, if not, whether the public interest would be served by legislation or administrative rules designed to assure more effective competition.

At the outset, it was determined that the interest of the public in a comprehensive, objective study of the complex broadcasting industry would be best served by a "study" technique, in addition to the formal hearing procedure provided under the 
Communications Act ${ }^{5}$ and the Administrative Procedure Act. ${ }^{6}$ The study technique included the following steps: a series of conferences with each component of the industry, at which the component made a presentation before the entire staff, explaining its functions and the problems in the industry as seen from the point of view of that component; extensive staff interviews with groups of stations, advertising agencies, national representatives of stations, independent program producers and distributors, and networks; a substantial spot-check of the networks' files; preparation and submission of extensive questionnaires ${ }^{7}$ to television networks, all commercial television stations, 60 advertising agencies, 34 national representatives of stations, and all independent program producers and distributors. These data and materials were then analyzed, resulting in the findings and recommendations contained in the report.

By using the study technique, it was possible to obtain much more information on the issues studied than would have been possible under the formal hearing type of proceeding alone. Thus, a comprehensive, deep, and sound study was made possible. Collation of the data entailed an extensive expenditure of manpower, particularly by networks, television stations, and independent program producers and distributors. The cooperation of the industry in this phase was excellent. Preparation by the industry of the data was a distinct public service.

Resistance to supplying data was limited to a number of the independent program producers and distributors who feared that the data, some of which was of a competitive business character, might become available to their competitors and, thus, injure them. While the request for the data was sustained by the Commission and the federal court, ${ }^{8}$ time lost in negotiations and litigation of this question prevented consideration in this report of some issues relating to programming. These will be the subject of a supplemental report by the Office of Network Study. ${ }^{9}$

The first phase of the inquiry was accomplished through the study technique. With the announcement by the Commission of the hearings on the findings and recommendations of the report, the second phase of the inquiry has begun. It should be observed that division of the inquiry into study and hearing phases should result in time-saving rather than delay. Now that the study has been made, the formal hearings can be conducted more expeditiously than otherwise would have been possible. Moreover, changes in the statute and rules relating to the complex and important broadcasting industry should only be considered in the light of a comprehensive and deep study of the structure and practices in the industry and the effect of proposed changes on broadcasting service in the public interest.

5 ${ }_{48}^{8}$ Stat. 1064 (1934), as amended, 47 U.S.C. $\$ \$$ I5I et seq. (1952).

- 60 STAT. 239 (I946), 5 U.S.C. \$ 1004 (I952).

${ }^{7}$ Indicative of the scope of the questionnaires is that more than 100,000 IBM cards were required to codify the data on the television station questionnaire alone.

${ }^{8}$ FCC v. Cohn, 154 F. Supp. 899 (S.D.N.Y. 1957).

- FCC Order 57-1076, released Sept. 27, r957. 
IV

\section{Findings and Recommendations}

\section{A. History and Description of Components}

As "past is prologue," the report begins with a brief history of the development of television and a description of the functions of the components of the industry. This is included as an aid to understanding the complex problems which are considered in the report.

\section{B. Public Interest}

The touchstone of the Communications Act is broadcasting in the public interest. Since a prime purpose of the study was to determine to what extent the existing structure and practices promote or impede the public interest in broadcasting and the commission policies which have given substance to this standard, the report next includes an analysis of court and commission actions in all decisional contexts. Service to the public is the ultimate goal of the broadcast regulatory function. The essence of broadcasting service is programming. In the implementation of this public service goal, the Commission has emphasized three basic supporting policy themes: competition, diversification of ownership of stations, and licensee responsibility. The Commission seeks the development of a nationwide broadcasting system and, to this end, encourages competition among networks for affiliates, competition among stations for network affiliation, and new entry into broadcasting. Television is a mass medium of communication and has great impact on our society and the mainstream of American thought and culture. Recognizing this, the Commission seeks the greatest diversification of ownership of stations in order to maximize service and program viewpoints and opinion sources. As the responsibility of the broadcaster is to render the best practicable service to the community served, and a person with "grass roots" in the community is deemed more knowledgeable of community cultural, civic, and business needs, the Commission also favors local ownership and control.

\section{Network Concentration of Control}

The first issue considered in the report is whether the degree of concentration of control by networks within the telecasting industry is consistent with the public interest.

In measuring concentration, the "market" has been defined as the national television advertising market. The essential business function of a television network is to provide a national advertising medium. It is the only national advertising medium using sight, sound, and motion, and other media are considered complementary rather than substitutable.

Network concentration in all relevant market dimensions has been measured in the report. In one significant dimension-the proportion of network programs during prime evening hours on television stations throughout the country-network con- 
centration is very high. During the three prime evening hours subject to network option, the three networks account for 80 per cent. In the case of basic stations of CBS and NBC, the proportion is over 90 per cent. The three networks account for a high proportion of national television time sales- -70 per cent. In other dimensions, such as total industry assets, total industry revenues, and proportion of networkproduced programs shown on the network, network concentration is not particularly high.

There is little prospect that the degree of concentration can be reduced by entry of new nationwide networks until there are substantially more comparable station facilities than now exist in the top 50 or roo markets in the country. While networking profits have risen to high levels in recent years, there are major obstacles to new entry. These barriers arise in part from the network-station affiliation arrangements, the existing structure of AT\&T rates for interconnecting stations and availability of AT\&T lines, and economies of large-scale operations. The principal factor, however, is the shortage of competitive TV station facilities in the VHF spectrum. Absent major technological change, such as the development of UHF into a competitive portion of the spectrum, networking will continue to be characterized by a small number of nationwide networks and high concentration.

There is a prospect of development of limited, special-service networks such as National Telefilm Associates (film network), the Sports Network, and Program Service, Inc.

Under present circumstances, however, the principal potential competition with networks must come from the national spot system of broadcasting. A typical advertiser, in consultation with his advertising agency, may decide to obtain a nationwide audience by sponsoring a program in one of the time segments available on the network. As many stations as are necessary to secure the desired coverage are ordered. The program for the time segment may be chosen from offerings of the network or independent program producers. The network clears the time segment with the affiliated stations and notifies AT\&T of the lineup. Alternatively, the advertiser and agency may decide, in lieu of network broadcasting, to use national spot advertising. The advertiser under this system places spot commercials on as many individual stations as it desires to order, and the time periods are cleared through the national representatives of stations. If a program is sponsored on national spot, this will usually be obtained from an independent producer and distributor. Thus, the national spot system of broadcasting competes with the network broadcasting system. Opportunity for effective competition between the network and national spot systems is affected by network practices in affiliation, option time, rates, compensation arrangements, "must buy," and other relationships with affliated stations.

Some of the recommendations in the report are intended to increase opportunities for competition between the network and national spot systems of broadcasting. 


\section{Affliation}

Affiliation of a station with a network, with some exceptions, largely determines the station's economic well-being and its program service to the public. The economic factor gives the network a superior bargaining position to that of most stations in making the affliation contract. The program-service factor has implications for the licensee's programming responsibility. Hence, a searching appraisal of network affiliation practices has been undertaken in the study.

In advertising, "cost per thousand" is a necessary factor, as the network provides a nationwide advertising medium, and in selecting its affiliates, the network is guided by economic considerations such as market size and unduplicated station circulation. Business interest has dictated that it rely largely on VHF facilities and, normally, that it not interconnect the small markets or UHF stations competing with VHF stations. CBS and NBC have developed special plans designed to encourage advertisers to order small markets. However, these plans have not solved the problem of the broadcaster in the small market. Also, where an affiliate "overshadows" a smaller market, the "overshadowed" market is usually excluded because the advertiser does not desire duplication of coverage. In choosing among stations in a market, the networks prefer that television station held in common ownership with the radio station affiliated with the related radio network. Also, at least one network has favored multiple-station owners in affiliation. These practices affect the development of UHF stations and stations in small or overshadowed markets and, to the extent that such development is so impeded, impinge on the Commission's policy of providing a nationwide, competitive broadcasting system.

To assist nonaffiliates and overshadowed stations in obtaining network programs, the report recommends that where the affiliate rejects the program and the advertiser desires another station in the same community, or where the advertiser desires the overshadowed station, the network be required in good faith to attempt to place the program on such other stations.

To assist affiliates not ordered by the advertiser in obtaining network programs, it is recommended that comments from all interested parties be obtained on a proposal that the network be required to make the program available to any unordered, affiliated station upon deletion of the advertisement and reasonable compensation to the network and advertiser.

To encourage competition between stations for affiliation, it is recommended that the network be required to file with the Commission its criteria for affiliation and disaffiliation and the basis for any change in affiliation, and that the network be prohibited from using as a criterion of affliation or disaffliation the fact that a licensee is the owner of more than one television station.

It has been recommended that the existing rules permitting an affiliate to have a right of first call and a right of territorial exclusivity on the network's programs in the same community and the present two-year maximum affiliation term be retained. 


\section{E. Option Time}

A major controversy has centered around the provision in affliation contracts that the affiliate will accept and broadcast all network programs offered to it during certain hours of the broadcast day, known as network "option time." Option time to some extent limits the exercise by the station licensee of his responsibility to select programs. To the extent that, through the option-time arrangement, the broadcaster is required to accept network programs which he would not otherwise be disposed to carry, the responsibility of the licensee to program in the public interest has devolved upon the network. Other business groups competing with networks have been placed at a competitive disadvantage by option time. Thus, independent program producers and distributors, a program source for stations using national spot advertising, have limited access to preferred viewing hours.

Network spokesmen have contended that option time is necessary to network operations. ${ }^{10}$ It is not apparent that option time is necessary to network operations. Stations clear for a substantial number of network programs in nonoption hours. Some "erosion" of clearances may occur without option time, as stations make their programming decisions with greater freedom. However, leverage to assure sufficient clearances for sound network service is provided by other factors. The station needs the network programs and national advertising revenue. The network needs the station for interconnection. Mutual interest assures reasonable cooperation. On the other hand, if the station did not need the network, the option-time arrangement would not assure a network service. With or without option time, the basic assurance of sound network service is that it has proved itself to be an economical and efficient national advertising medium. Leverage for clearance of network programs is provided also by the network's bargaining position in setting rates, negotiating compensation arrangements, and in establishing the "must buy" list. However, leverage from these fulcra would be diminished if recommendations with respect to them should be adopted.

Moreover, there is a possibility that the option-time practice would be found to be a per se violation of section one of the Sherman Act, ${ }^{11}$ on analogy to the motionpicture "block-booking" practice condemned in the Paramount case. ${ }^{12}$ A limited number of network programs are apparently forced on the station under the optiontime practice. Were this not so, the network would have no need for option time. If the option-time practice is questionable under the antitrust laws, it should not be permitted under the Commission's rules, because the Commission seeks that level of competition in the industry which promotes the public interest, a broader standard of competition than is provided under the antitrust laws.

The report recommends that the option-time practice be prohibited by rule.

${ }^{10}$ Following release of the report, some network officials were reported in the trade press as stating that without the option-time practice, networks, over a period of time, would be destroyed. For example, sec Broadcasting, Nov. 25, 1957, p. 64.

1126 STAT. 209 (I890), I5 U.S.C. $\S$ I (x952).

${ }^{12}$ United States v. Paramount Pictures, Inc., 334 U.S. I3r (I948). 


\section{F. Rates}

A significant function of networks under the affiliation contract is establishing the time rate of each affliate for sales to network advertisers. The study concludes that this network function is necessary for various reasons, including the fact that the network must translate circulation data into a rate structure which is competitive with other networks and other advertising media. In general, the interest of the network and station in rate-setting is compatible.

Some practices in rate-setting, however, conflict with Commission policy. For example, it has been found that networks have sometimes used rate decisions as a lever in obtaining clearances and discouraging clearances for competing networks. On the other hand, a station in a highly favorable position may make clearañce conditional on a desired rate increase. These practices are contrary to the public interest because clearance should be based on judgment as to the quality and suitability of competing programs.

Furthermore, in the study it was found that some networks have used their power to fix network rates so as to influence the stations' national spot rates. In such instances, the network objective has been to have the stations raise the national spot rate so as to decrease the power of national spot to compete with the "networking" system. This practice violates a commission rule and has antitrust ${ }^{13}$ implications. No evidence of this practice in recent years, when the rates for the two systems have been substantially, equal, has been found. However, some other questionable rate practices were found.

It would be undesirable for broadcasting to be subject to rate regulation by the Commission. However, some measure to prevent the rate practices mentioned is necessary. To achieve this, it has been recommended that the self-regulating force of publicity be utilized by requiring the networks to publish their rate-making procedures, circulation credited to each station, formula used for rate-making purposes, and all rate changes. It has been further recommended that a rule be adopted prohibiting networks from attempting to influence the national spot rate of affiliates and from setting network rates to influence station decisions with respect to clearances.

\section{G. Compensation}

The revenue obtained from network time sales is shared between the network and its affiliates on the basis of a compensation formula specified in the affiliation contract. Typically, the station waives compensation for a designated number of "free hours" after which the station receives a specified share of its card rate, usually about $3^{\circ}$ per cent. The study does not find that the network share is unreasonably large, since, out of its 70 per cent, the network must make substantial payments, such as discounts to advertisers, commissions to advertising agencies, and

${ }^{13}$ This matter has been referred by the Commission to the Department of Justice for consideration of the antitust aspects. 
interconnection costs. Stations in large markets earn a substantially higher profit ratio than do networks.

There have been found differences in compensation arrangements with affiliates. Usually these are based on reasonable competitive situations, but sometimes they are affected by considerations such as a more favorable compensation arrangement for improvement in station clearances. Program clearances should be based only on program quality and suitability. Sliding-scale or incentive types of compensation are subject to serious program-clearance abuse.

As a self-policing factor in this area, it has been recommended that the affiliation contracts filed with the Commission, containing compensation arrangements, be made public.

\section{H. "Must Buy"}

The study includes the "must buy" practice of CBS and NBC and "minimum buy" practice of $A B C$. CBS and NBC require that an advertiser using the network order a group of stations, about 55 in number, designated by call letter. This group is called the "basic" stations, and the basics must be ordered. ABC does not follow a "must buy" practice but requires the advertiser to order stations having card rates which, in the aggregate, equal a "minimum buy" in dollars.

Usually the advertiser orders a much greater list than required under the "must buy" or "minimum buy" arrangements. The problem from the advertiser's point of view comes when he must take, under the "must buy" arrangement, specified stations which he does not desire.

However, there is a stronger objection from the standpoint of commission policy. Stations are anxious to be included on the "must buy" list because this assures financial success. At the margin, the stations are willing to concede much for this privilege. The network makes the decision as to inclusion in the "must buy" list. This gives the network an additional bargaining advantage in the matter of clearances. As a consequence, some stations are led to accept programs which they otherwise would not be disposed to carry.

Independent stations have sometimes charged that they are placed at a competitive disadvantage by "must buy." There is no evidence that this is so. Of course, independent stations have little opportunity to carry network programs. But this results from the affiliated station's right of first call on all network programs.

CBS and NBC spokesmen have taken the position that "must buy" is necessary to define a national package and to prevent fragmented sales of network time on an uneconomical basis. However, the study finds that it is the advertiser's need for national coverage which assures a nationwide lineup. If advertisers did not need this, networks could not enforce it through "must buy." ABC operates with a "minimum buy."

Moreover, an antitrust analysis of "must buy" raises doubt as to its legality under section I of the Sherman Act. "Must buy" is similar to the "tie-in" arrangement in 
the Times-Picayune case, ${ }^{14}$ the tie-in arrangement described in United States $v$. Northern Pacific Railway Co. ${ }^{15}$ case, and the "block-booking" formula prohibited in the Paramount case, supra.

It has been recommended that the "must buy" practice be prohibited but that a "minimum buy" arrangement such as $A B C$ uses be permitted and that the size of the "minimum buy" be left to business judgment.

I. Network Representation in National Spot

CBS and NBC represent a small group of affiliated stations, as well as their owned and operated stations, in national spot sales.

As previously mentioned, national spot competes with the network broadcasting system. A question arises as to whether the public interest is served by having networks engage in representation of stations in the national spot field, when this is a direct competitor. Also, as previously mentioned, the study found that some networks have influenced the national spot rate through their power to set the rate of the station for network sales. The study disclosed no affirmative reasons why networks should represent any station, other than their owned and operated stations, in national spot.

It has been recommended that networks be prohibited from representing stations, other than $\mathrm{O} \& \mathrm{O}$, in national spot.

\section{J. Multiple Ownership}

Commission policy has sought to achieve for stations the character of local institutions having a "grass roots" interest in the service and program needs of the community. Also, it has enunciated a doctrine of diversification of ownership to maximize opinion, program, and service viewpoints. These doctrines recognize the great impact of television on public opinion and culture. They point to a one-to-a-customer concept of station ownership. However, these doctrines have been balanced with others, such as that favoring an applicant with a sound record of past performance in broadcasting, resulting in the present multiple ownership rule. Under this rule, the same interest may own a maximum of seven TV stations, not more than five of which may be in the VHF band. Within this ceiling, the rule envisages consideration of each application on a case-by-case basis. However, in practice, the Commission has relied on the ceiling, and no applicant having fewer than the maximum has been denied a station on the ground of undue concentration. Where a licensee sells a station, the Commission is precluded from considering any other applicant than the one selected by the licensee, and such applicant must be accepted if he meets minimum standards of the Commission. One out of three stations held by multiple owners was acquired by transfer under statutory immunity from a comparative contest.

Notwithstanding the numerical limitation, multiple ownership has grown greatly, and the trend is toward a multiple-unit system. In the top roo markets, there are

16 Times Picayune Publishing Co. v. United States, 345 U.S. 594 (1953).

${ }^{18}{ }^{142}$ F. Supp. 679 (W.D. Wash. 1956). 
185 VHF stations, of which 104, or 56 per cent, are held in multiple units; and $5^{2}$ UHF stations, of which only 17 , or 33 per cent, are multiple-owned. Most television stations are held in common ownership with radio stations and, to a substantial degree, with "cross-channel" media as well.

Multiple owners concentrate their holdings in the large, profitable markets. The concentration in such markets is very high and should be a matter of grave concern. As of November 1956 , in the top 25 markets, 70.7 per cent of VHF stations were held in multiple units. Twenty per cent of the stations were single VHF units held in common ownership with "cross-channel" media, newspapers; 9.3 per cent were single VHF units not related to newspaper interest. The percentage held by multiple owners is slightly higher today. It must be recognized that in the top 25 markets, the diversity of ownership doctrine has been seriously eroded. Many important population centers have no single station operator. Many more have only one such operator, in most instances a newspaper-owned station. The top 25 markets serve more than half the population of the country.

By contrast, the pattern of ownership of VHF stations in the $7^{6 \text { th }}$ to rooth markets should be noted. Here the stations held in multiple units drop to 34.3 per cent. The single units comprise 65.7 per cent, about one third of which are newspaperconnected. ${ }^{16}$ It is thus seen that the relative holdings of multiple and single-station owners in the top 25 markets and the 76 th to Iooth is almost precisely reversed.

The pattern of ownership in all the top roo markets is that multiple ownership decreases in rough proportion to the decrease in market rank, and single station ownership increases in rough proportion to the decrease in market rank.

Multiple ownership is still increasing. From January 1954 to July 1956 , multiple ownership in the top roo markets increased from $4^{\mathrm{I}}$ per cent to 50 per cent. During the course of the study, new groups such as feature film companies, investment concerns, and others indicated an interest in acquiring stations. Telecasting is profitable, and it is likely that entry of new interests will accelerate the growth of multiple ownership.

Acquisition of viable VHF stations can only take place through the transfer route, since substantially all VHF channels have been granted. It is interesting to note the effect of sale of TV stations on the type of ownership. From January 1956 to July $1957,26 \mathrm{TV}$ stations in the top 25 markets were sold and 22 of the 26 were acquired by multiple owners. Again, by contrast, the sales in the 76 th to rooth markets are noted. Of $2 \mathrm{I}$ stations transferred during the same period, II were acquired by multiple owners. The increase in multiple ownership in this bracket was very substantial but not nearly so great as that in the top 25 markets.

The pattern and trend in station ownership definitely is toward a multiple-unit system of broadcasting. Within the limits imposed by the Commission, this trend must be expected to increase. The image of an individual station-owner, devoting

${ }^{10}$ The UHF pattern is similar. In the top 25 markets, multiple owners held 5 of the 6 U's; whereas, in the $7^{6 \text { th }}$ to rooth markets, multiple owners held only 3 of the $1_{3}$ U's. 
his efforts in television to serving a single community he has been licensed to serve, is a myth for most large cities, and hence for the majority of the listening public of the United States.

Multiple owners; by bargaining with networks, national spot representatives, and independent program suppliers for their group of stations as a whole, obtain a competitive advantage over single station-owners in the same communities. This is not to say that all multiple owners have such advantages, or that any one enjoys all advantages accruing to the others. By way of example, the rate of compensation to a national station representative is frequently based on a sliding scale, so that the rate for the first $\$ 500,000$ annual business may be 15 per cent, for the next $\$ 500,000-10$ per cent, and for sales in excess of $\$ 1,000,000-5$ per cent. In a number of cases, multiple owners have been permitted to combine their station sales, with obvious advantage over single-station owners in the same markets. The competitive advantage obtained by multiple owners may be a factor in the growth of multiple station units.

Networks are currently permitted to own stations to the same extent that other multiple owners are, and most of their stations are concentrated in the largest markets. They were initially permitted to own stations because this was a source of revenue to sustain the networks during their early development, and the stations provided theaters for the development of talent and program ideas. Today networking in itself is profitable, and most program development takes place in the network program departments. Also, there are conflicts of interest between network and station operation. In addition, ownership by networks in top markets is a further limitation on entry of new networks. Nevertheless, the study has recommended that, for the present, networks and other multiple owners be subject to the same multiple-ownership limitations. This is out of caution lest the ability of networks to provide quality programming and to experiment with new program concepts be limited, contrary to the public interest. The extent of the divestiture of stations by networks provided for under the recommendations should raise no concern ${ }^{17}$ as to the ability of networks to provide programming and information of a quality and quantity consistent with the public interest.

The recommendations as to multiple ownership are as follows:

I. That the present numerical limitation be amended to provide that no multiple owner be permitted to own more than three VHF stations in the top 25 markets. A reasonable period of time, such as three years, should be allowed for sale of stations divested.

2. That in granting original applications the Commission establish a legal presumption in favor of local applicants and an applicant who owns no other television station.

3. That the statutory preclusion of comparative proceedings in transfer cases be

${ }^{17} \mathrm{~A}$ network official has stated that the cumulative effect of the recommendations could so weaken networking that the networks could not sustain informational activities at the present level. Broadcasting, Nov. 18, 1957, p. 91. 
repealed in order that in the case of transfers, the Commission may consider all applicants in a comparative hearing; that in transfers, the Commission require that the prospective purchaser make his offer in a stated dollar amount in order that others may match the offer and be considered in the comparative hearing, thereby avoiding the more difficult problems in the "Avco" procedure; and that in such hearing, the Commission give effect to presumptions favoring local applicants and. nonowners of television stations.

4. That to slow down the trafficking in stations, no person be permitted to acquire a second television station until he has operated a station for a full term, thus preventing block sales of several stations to interests new to television.

\section{K. Application of Rules to Networks}

At present the Chain Broadcasting Rules of the Commission apply directly to. stations and only indirectly to networks. The rules say that a station's license will not be granted, and hence will be revoked, if it enters into a contract or agreement with a network permitting proscribed practices. However, the rules were adopted to. achieve for stations freedom from undue network influence in designated respects, so that the stations might exercise their responsibility to broadcast in the public interest.

Networks have contributed greatly to the public interest in broadcasting. However, some of their practices have been found contrary to the public interest. Substantially all of the recommendations made in this report relate to conduct or potential conduct of networks. There are administrative and practical difficulties in effectuating commission policy through application of some of these recommended rules to. stations. In some instances, as in the case of the recommendation that "must buy" be prohibited, there may well be a legal difficulty as well. This arrangement is betwreen the advertiser and network-not the network and the station.

Moreover, the best atmosphere for enforcement of rules is lacking when the sanction applies to the party on which the proscribed conduct is imposed, rather than to the party responsible for the conduct. The existing regulatory approach would appeal to Gilbert and Sullivan.

Power and responsibility go hand in hand; not weakness and responsibility. Decisions are more responsible when those who make them are answerable to those affected by the decision and to the public. The networks, which are the strongest decision-making component in the television industry, should be answerable to the viewing public through commission policies expressing the public interest.

Accordingly, it has been recommended that the Commission seek express congressional authority to apply its rules directly to networks.

\section{Sanctions}

The only sanction which the Commission currently may apply is revocation of the broadcaster's license. This is a drastic penalty. In the Don Lee case, ${ }^{18}$ in which

${ }^{18}$ Don Lee Broadcasting System, 5 Pire \& Fischer Radio Regulations ii79 (i950). 
the Commission was dealing with clearcut violations of the Chain Broadcasting Rules, the Commission concluded that revocation of any station licenses would be too extreme a penalty.

The punishment should fit the crime. The study recommends that the Commission seek congressional authority to adopt a system of forfeitures commensurate with the nature of the infraction.

\section{V}

\section{ConCLusion}

The report accepts the network system as a necessary and highly desirable component of the American broadcasting system. It was the nationwide, interconnected network system of broadcasting, providing "free" program service through national advertiser support, which made possible the phenomenal growth of television in our country. It brought national program service to substantially all our people in a brief span of years. Through this system, public-service programming as well as popular entertainment is provided, and simultaneous broadcast to a nationwide audience of events of national public interest is made possible. In these and other respects, the networks serve the national public interest.

On the other hand, there are respects in which the networks' concentration of control and practices have been found incompatible with the public interest. To achieve more effective competition, the Network Study Staff, in lieu of considering basic structural changes, has followed the policy of working within the framework of the existing network system and recommending the minimum changes necessary to remove competitive restraints and to effectuate commission policy relative to licensee responsibility, diversity of ownership and control, and broadcasting in the public interest. Thus, it has been recommended that the self-regulating value of publicity as to affliation practices, rates, and compensation be relied upon to the greatest extent possible. Where this is not feasible, it has been recommended that the restraints on station freedom and the competitive opportunities for nonnetwork groups, resulting from option time, "must-buy," the use of affiliation and rate decisions to influence station clearances, and other practices, be prohibited or further limited. The recommendations are designed to improve upon the existing structure, rather than to provide a substitute for it.

Through these recommended changes, stations would have additional freedom in programming to meet the needs of their local communities; there would be somewhat greater opportunity for access to the valuable television medium of nonnetwork groups, such as program producers and national station representatives, thereby providing a wider range of program choice; some greater access of local and regional advertisers to television would be provided; multiple ownership would be reduced, and more entrepreneurs would be brought into broadcasting, thus increasing opinion sources and the opportunities for local community service; and the 
networks would be subject directly to the Commission's rules, so that any restraining conduct in matters affecting the public interest might be more effectively administered. Adoption of the recommendations should result in a greater degree of competition in broadcasting, programming which is more responsive to community needs, and a more nearly nationwide service. The viewing public would have available a wider variety of television services and a more varied program fare.

In the opinion of the Network Study Staff, these recommendations, if adopted, will bring about important and substantial improvements in television broadcasting service to the people. 